\title{
Tourist Towns from the Perspective of "Slow City" Model---A Study of Planning and Design of Waterfront Space in Fuliang County, Jingdezhen
}

\author{
Xiaoli $\mathrm{Yu}^{1,}$, , Ying $\mathrm{Li}^{2, \mathrm{~b}}$ and Xin Zhou ${ }^{3, \mathrm{c}}$
}

${ }^{1}$ Design and Art School, Jingdezhen Ceramic Institute, Jingdezhen, Jiangxi Province, China

${ }^{2}$ International School, Jingdezhen Ceramic Institute, Jingdezhen, Jiangxi Province, China

${ }^{3}$ Design and Art School, Jingdezhen Ceramic Institute, Jingdezhen, Jiangxi Province, China

a2006yuxiaoli@163.com, beagle05fly@163.com, ‘506695633@qq.com

Key Words: Tourist Towns, "Slow City" Model, Planning and Design, Waterfront Space

Abstract: With the development of new types of urbanization in China, the layout and planning of towns is increasingly influenced by large cities and the design of towns tends to be the same as that of cities. As an emerging city construction model, "Slow City" model is devoted to protecting the original natural scenes of cities, carrying forward traditional culture and redefining native culture. Through the study of planning and design of waterfront space in Fuliang County, Jingdezhen, guided by the concept of "Slow City"model and the experience of successful cases of "Slow City" model in the world, this paper tries to design the slow traffic system and slow tourism space in Fuliang County.

\section{Introduction}

As the process of urban and rural integration is accelerating, small towns have a great room for development. But so far, the construction of most of tourist towns has been lack of professional guidance and systemic planning. Thus, it is vitally important to construct a tourist town which has well-established system and well-equipped facilities and also meets the need of local residents and tourists.

The $18^{\text {th }}$ National People's Congress has put forward a new notion, which is to balance rural and urban development and to promote mutual prosperity. Although the living standard of rural and urban residents has been improved, people become more and more aware of the fast pace of urban life, great pressure and insufficient leisure time, all of which fails to satisfy individual developments both physically and mentally. Under the circumstance, the emerging "Slow City" movement in Europe inspired the writer to do research on the planning and design of tourist towns.

\section{"Slow City" Model \\ "Slow City" movement}

"Slow City" movement was emerged in Europe, which was proposed in 1999 during the first "Slow City" meeting in Oviedo, Italy where they announced Cittaslow International Charter aiming at building a new model for city. "Slow City" is popular among foreign countries, which advocates returning to green and natural life, relieving the pressure, seeking a balance between physical and mental needs, and pursuing life of higher quality.

\section{The concept of "Slow City" model}

"Slow City"model integrates the urban construction concept towards nature and ecology into urban development, and promotes specific implementation plans. It focuses not only on the protection and construction of natural and man-made environment in the city, but also on the 
advocacy of resources recycling, exploitation of new energy and control and resolution of urban pollution.

"Slow City"model lays emphasis on traditional culture and featured construction. It attaches importance to the preservation and development of historical and traditional scenes, emphasizing the inheritance of traditional techniques and the slow speed in all the process. Although it pursues slow speed, it neither completely denies the fast speed in modern society, nor advocates to slow down all the developments. It is to find the form and meaning of the "slow" in the fast pace of modern life. It applies modern advanced science and technologies to modern urban life, in order to provide convenience for its people. In many aspects, "Slow City"model is in the forefront of modernization.

\section{The feasibility of the application of"Slow City"model to Chinese tourist towns}

\section{Cultural basis}

Although "Slow City"model is a new notion in China, the history of "slow" philosophy in China is long. The five ways, such as reading books, burning incense, drinking tea, appreciating flowers and playing musical instruments, are used by ancient Chinese to release stress and to pursue slow lifestyle. Many small historical towns in China, such as Lijiang in Yunan province, Wuzhen in Zhejiang province, are followers of "Slow City"model, maintaining slow pace of life.

\section{Material basis}

Undamaged by industrial revolution, many Chinese towns has preserved its natural scenery, traditional architecture and folk customs, which are in line with the original and ecological tourism sought by modern people. The concept of "Slow City"model and that of the development of towns are highly complementary, and the combination of the two concepts together will create new economic value. On the one side, local features and traditional culture are indispensable for building a slow city. On the other side, the development of a slow city lays a basis for protection of ecological environment and inheritance of traditional culture.

\section{Policy basis}

Chinese central government has put forward a plan that a new, green and intellectualized urbanization path should be followed. The 12th five-year plan has proposed the goal of development, which is based on large cities, focusing on small and medium-sized cities, so as to promote sound and green development of urbanization. It is encouraged to explore new features of towns with abundant local culture so as to build towns with distinctive surroundings and regional culture. Based on actual situation, "Slow City"model meets with the requirements of new urbanization. 


\section{Design and study of waterfront space in Fuliang County, Jingdezhen under the influence of "Slow City"model}

\section{The current situation of waterfront space in Fuliang County, Jingdezhen}

\section{Not enough attention being paid to landscape construction}

According to Chinese national standard, the width of green land in waterfront space must be at least 8 meters. Through on-the-spot investigations in Fuliang County, it is found that the width of its green land in waterfront space is insufficient, which not only fails to play its role as green path, but also fails to provide enough public space for tourists and residents.

\section{Weak performance of public space}

Investigators discovered that there wasn't enough waterfront space in Fuliang County for users to do outdoor activities and various needs of residents and tourists couldn't be met. The design of waterfront space should show clearly the characteristics of being complicated and integrated with functional continuity. While urbanization in China is increasingly accelerating, many parts of waterfront space in Fuliang County are occupied and lack of completeness and continuity owing to urban development and construction.

\section{Incoherence with internal traffic}

For lack of a united planning, traffic among waterfront space in Fuliang County is impractical and some roads and paths are cut off. Not merely will this weaken the link between the river and its outer space, but also it's incapable of providing comfortable leisure space for human being.

\section{Incomplete public facilities}

The public facilities of waterfront space in Fuliang County are incomplete and its layout is irrational. The designs of seats, trash cans and street lamps don't take the users and surroundings into consideration and some of them don't act in cooperation with surroundings in the same space. Besides, most of waterfront space lacks humanistic concerns. Although different groups have different demands for the space, it is found that only a few public facilities highlights the concern on special groups, children and the elderly.

\section{Improvements on waterfront space in Fuliang County based on "Slow City" model}

\section{Strengthening vitality in waterfront space}

In order to strengthen vitality in waterfront space, the polluted water should be disposed in the first place. Drawing on successful cases of "Slow City"model, self-purification capacity should be improved and variety of aquatic species in this region should also be maintained. Revetment is the junction between water and land. Therefore, the design of revetment should be simplified so as to reduce interference from artificial revetment to rivers.

\section{Keeping features of natural landscape}

"Slow City"model advocates to preserve and protect traditional features of natural landscape. This concept can be applied to the improvement of waterfront space in Fuliang County, highlighting the characteristics of the town. "Slow City"model emphasizes the importance of protecting natural 
scenery and its features. One case is the complete preservation of natural scenery in Gaochun International Tourist Area. In the renovation of waterfront space in Fuliang County, the natural scenery along the river should be preserved so as to keep traditional scenery and to display local unique features in this area.

\section{Designing a humanized space}

Waterfront space is an important landscape element in the city and a major place for outdoor activities and entertainment. Designing a humanized waterfront space is a significant step for building a tourist town. It can be achieved through many ways, such as optimizing touring routes and strengthening the traffic convenience. It is worth studying the designs of spaces in many successful cases influenced by"Slow City"model, which advocates people-oriented and starts from people' needs. The design of waterfront space in Fuliang County should create slow traffic space with existing conditions, installing a wide array of entertainment facilities around the river, linking every bend and point of the river with main streets and adding "green lane" elements to form featured street landscape.

\section{Establishing slow traffic system}

Compared with big cities, infrastructure in towns is relatively backward. Thus, it is crucial to establish slow traffic system for a slow tourist town. In waterfront space in Fuliang County, the slow traffic system with bike paths and sidewalks should be established to separate pedestrians from automobiles, which could be divided into two parts, the external and internal path. Connected with main streets in Fuliang County, the external path is for cycling and entrance and exit doors should be installed in the areas with large flows of people. The internal path is for walking and signs of touring routes should be set up in different tourist attractions to slow down the pace of visitors. Space for communication and relaxation should be added along the internal path. When designing the paths, safety should be ensured and the aim of making people feel comfortable when walking slowly on it should be achieved.

\section{Implementation strategies on waterfront space in Fuliang County based on "Slow City" Model}

\section{Colors of landscape}

Studies have shown that people have different feelings towards different colors. People tend to be excited and passionate when faced with warm colors, while they seem to calm down when confronted with cool ones. Except that some intense colors should be used in some special areas in waterfront space in Fuliang County, colors in other areas should make people feel at ease. Ground pavement and plants have a considerable impact on people because they operate as the compound color in the space. In static space, colors with low purity and brightness are suitable for relaxation and reading. While in dynamic space, bright colors should be added in key landscape nodes so as to break flatness of colour in this area. Some parts of the waterfront space should be designed for particular groups. For example, in children's playing area, a great variety of bright and lively colors should be used to meet with the lively and active nature of children. 


\section{Plants}

"Slow City"model advocates to create landscape with its regional features. Therefore, the arrangement of plants in waterfront space in Fuliang County should embody the regional characteristics, follow the principle of natural laws and show the beauty of nature. "Slow City" model suggests that during sightseeing, tourists should slow down and be closer to the nature. Thus, plants in waterfront space must be poisonless and harmless. According to "Slow City"model, the natural state of plants should be kept and fresh flowers and trees should be chosen instead of plastic ones.

\section{Ground pavement}

Ground pavement has unique spatial characteristics. It is a part of slow traffic system and has dual function of environmental art and guide."Slow City"model encourages designers to combine artificial landscape with its surroundings, so relatively natural, rough textures, such as textures with lichee pattern and pineapple pattern should be adopted to ground pavement of waterfront space in Fuliang County. Firstly, natural materials are more consistent with surrounding environment. Secondly, rough ground increases safety for walking and riding on it and adapts to the functional requirements of slow lifestyle which "Slow City"model tries to create.

Moreover, ground pavement has always been a symbol of national culture. In Gaochun, the first International "Slow City"in China, roads paved with flagstones run through the whole district, the style of which coheres with buildings on both sides, displaying its prolonged history. In Oviedo, Italy, streets are paved with ancient stones. Walking on the streets, tourists feel as if they were in the Middle Ages. As for ground pavement in waterfront space in Fuliang County, regional cultural elements should be added in to show unique characteristics of the town.

\section{Conclusion}

Under the background of new urbanization in China, the paper analyzes the feasibility of the application of "Slow City"model to Chinese tourist towns and the current situation of waterfront space in Fuliang County, Jingdezhen, It combines the design of waterfront space in Fuliang County with "Slow City"model and puts forward improvements and implementation strategies in this area. It is concluded that based on the protection of its original natural landscape, the design of slow tourism space in this area should add more traditional and regional culture in it, hoping to offer help and inspiration to following researches.

\section{References:}

[1]Parkins and Craig, Slow Living. Berg Press (2006)

[2]Liangjuan Culture, leisure Travel in Slow cities.Longmenshuju (2013)

[3]Guangdong Meizhou Cultural Tourism District Management Committee, Cittaslow Meizhou. Guangdong Tourism Press (2015)

[4]Leng Jing, "Slow City Movement in Fast-paced Era". Decision Making.Vol.12 (2010), pp. 74-74 [5]S Radstrom, "A Place Sustaining Framework for Local Urban Identity: an Introduction and History of Cittaslow”. Italian Journal of Planning Practice.Vol.09 (2011), pp. 67-79 
Note: The thesis is the stage result of the 2016 Jiangxi Province culture and arts and science planning general project "Tourism Cities from the Perspective of 'Slow City' -- Study on the Planning and Design of Fuliang County in Jingdezhen” (YG2016049) 